\title{
Knowledge Management Innovation For Sustainable Development in the Context of the Economic Crisis
}

\author{
Adrian Ioana \\ University Politehnica of Bucharest, \\ Science and Engineering Materials Faculty, \\ UPB'SIM, Bucharest, Romania
}

\author{
Augustin Semenescu \\ University Politehnica of Bucharest, \\ Science and Engineering Materials Faculty, \\ UPB'SIM, Bucharest, Romania
}

\author{
Cezar Florin Preda \\ University Politehnica of Bucharest, \\ Science and Engineering Materials Faculty, \\ UPB'SIM, Bucharest, Romania
}

Received: January 21, 2020. Revised: March 10, 2021. Accepted: March 16, 2021. Published: March 22, 2021.

\begin{abstract}
The trade (qualitative and quantitative level of trade) can promote the concept of sustainable development. The concept of Sustainable Development involves the implementation of theoretical and practical components for making decisions in any situation in which features a man-type medium, be it the environment, economic or social. The goals of sustainable development include the harmonization of the economic, social and environmental targets. This paper presents the main types of the correlations: Trade - Sustainable Development - Economic Crisis. The Sustainable Development (SD) concept is also analyzed in direct correlation with the Corporate Social Responsibility (CSR) concept. The SD concept involves the implementation of theoretical and practical components for making decisions in any situation in which a man-type medium, be it the environment, economic or social features. The Corporations (qualitative and quantitative level of trade) can promote the concept of sustainable development. The goals of sustainable development include the harmonization of the economic, social and environmental targets. This paper presents the main research on the main types of the correlations: Corporate Social Responsibility (including trade) - Sustainable Development - Economic Crisis.
\end{abstract}

Keywords- Management Innovation, Sustainable Development, Economic Crisis

\section{INTRODUCTION}

The world must quickly design strategies that will allow nations to move from their current, often destructive, processes of growth and development to sustainable development paths. This will require policy changes in all countries, with respect to both to their own development and to the impact on other nations' development possibilities (Ammann, 2002, Ioana, 1998).
The concept of sustainable development designates all forms and methods of socio-economic development, whose foundation is primarily to ensure a balance between these systems and socio-economic elements of natural capital.

Development is sustainable when it addresses the problem of the large number of people who live in absolute poverty that is, who are unable to satisfy even the most basic of their needs.

Poverty reduces people's capacity to use resources in a sustainable manner (it intensifies pressure on the environment).

Most such absolute poverty is present in developing countries (it has been worsened by the economic stagnation of the 1980s).

A necessary but not a sufficient condition for the elimination of absolute poverty is the relatively rapid rise of per capita incomes in the Third World. It is therefore essential that the stagnant or declining growth trends of this decade are reversed.

Growth must be revived in developing countries because that is where the links between economic growth, the alleviation of poverty, and environmental conditions operate most directly. Yet developing countries are part of an interdependent world economy; their prospects also depend on the levels and patterns of growth in industrialized nations.

Such growth rates could be environmentally sustainable if industrialized nations can continue the recent shifts in the content of their growth towards less material- and energyintensive activities and the improvement of their efficiency in using materials and energy. 
Sustainable Development involves achieving the current need without compromising the ability of future generations to meet their own needs.

The standard theory of economic development involves both quantitative change (increase in Gross Domestic Product) and qualitative change (shift from pre-capitalist economy based on agriculture to industrial capitalist economy $(1,3]$.

The theory of sustainable development involves both a critique of quantitative measure of GDP and a different vision of qualitative transformation. The goals of sustainable development include the harmonization of the economic, social and environmental targets.

The concept of sustainable development was born 37 years ago, as a response to the emergence of environmental and natural resources crisis, especially those related to energy. The Conference on the Environment in Stockholm in 1972 marks the moment when it is recognized for the first time that human activities contribute to environmental deterioration, which threatens the future of the planet $[7,11,12]$.

Sustainable development has become an objective of the European Union since 1997, when it was included in the Maastricht Treaty, and in 2001, the Summit at Goteborg adopted the Strategy for Sustainable Development of the European Union, which was added an external dimension at Barcelona in 2002.

Risk management in banking designates the entire set of risk management processes and models allowing banks to implement risk based policies and practices. They cover all techniques and management tools required for measuring, monitoring and controlling risks. The spectrum of models and processes extends to all risks: credit risk, market risk, interest rate risk, liquidity risk, operational risk and country risk.

\section{ABOUT THE TRADE FOR SUSTAINABLE DEVELOPMENT}

The most known definition of sustainable development is given by the World Commission on Environment and Development (WCED) report "Our Common Future", also known as the Brundtland Report [9]:

"Sustainable development is development which aims to meet the needs of present without compromising the ability of future generations to meet their own needs".

The concept of Sustainable Development involves the implementation of theoretical and practical components for making decisions in any situation which features a man-type environment, be it the environment, economic or social.

In the human-environment correlation (more precisely the human-environments correlation), the trade is of particular importance $[2,5,6]$. This importance is that the trade may affect (positively or negatively) all three types of environment (the environment/ ambient, economic and social environment). Figure schematically presents the importance of the trade for the human-environments correlation.

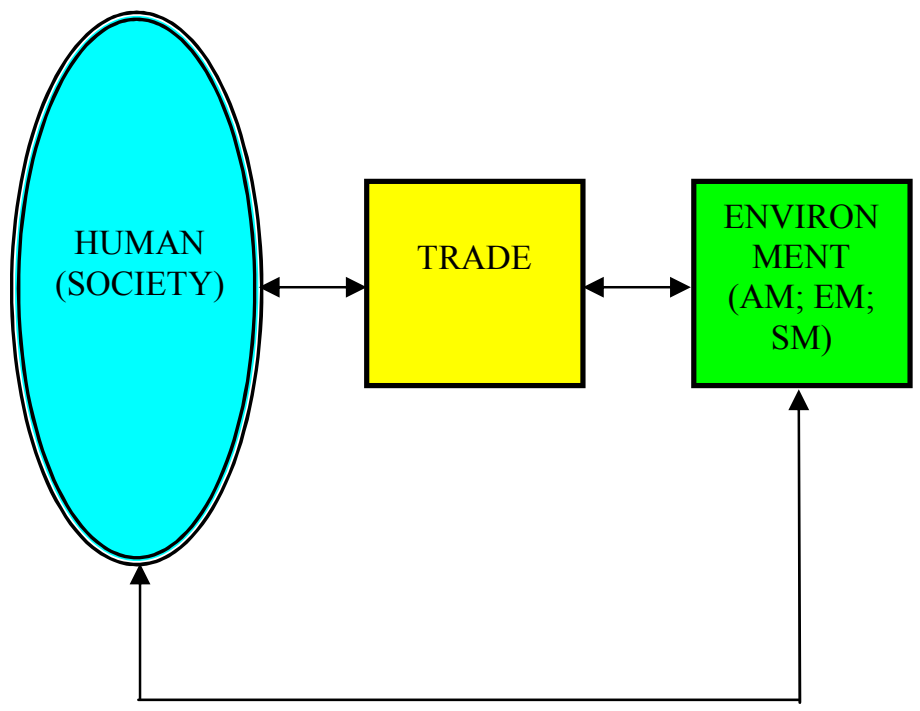

Fig. 1. The importance of the trade for the humanenvironments correlation.

AM - Environment (Ambient Environment);

EM - Economical Environment; SM - Social Environment.

The importance of trade in human-environments relationship is revealed by the central position of the trade.

The double correlations trade-man and tradeenvironments is also highlighting the importance of trade in this relationship.

For the detailing of the human-environment relationship schematically presented in figure 1, we may define two specific types of trade:

$>$ Ecological Trade ("Green Trade") in direct correlation with the environment (ambient). The Ecological Trade-Environment correlation consists of: the trade that applies and extends the requirements as to the protection of the environment positively influences the latter ( $\boldsymbol{\nearrow}$ ). Implicitly, under these circumstances, the ecological trade is the sustainable development generator (figure 2).

$>$ Social trade, in direct correlation with the social environment. This correlation suggests that a trade that puts the forefront of continually optimizing the price/quality ratio in terms of customer (that is the increase of this report without being affected quality) is a trade positively affecting $(\boldsymbol{\nearrow})$ the social environment.

The multiple correlation human (society) - trade environment - sustainable development is schematically in figure 3 . 


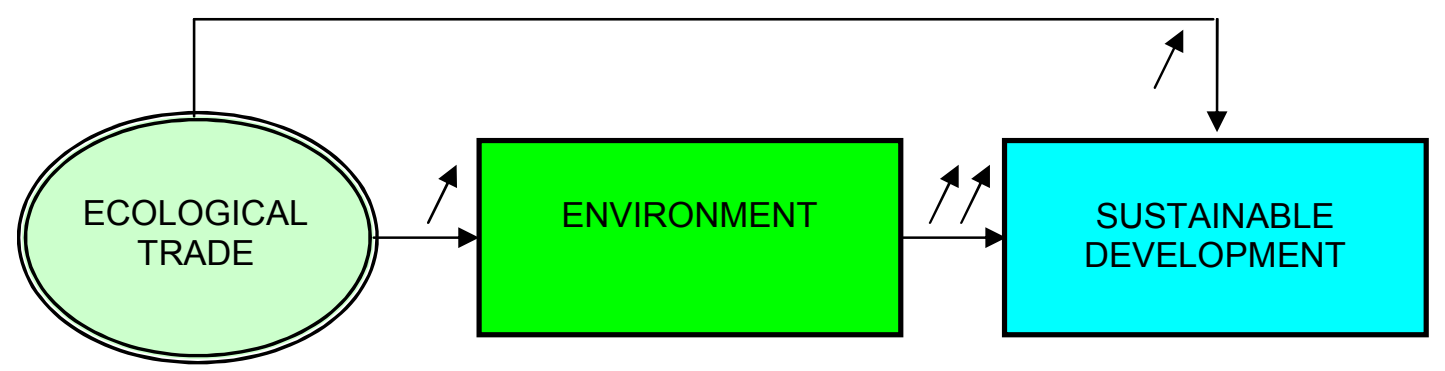

Fig. 2. Ecological Trade - Environment - Sustainable Development correlation

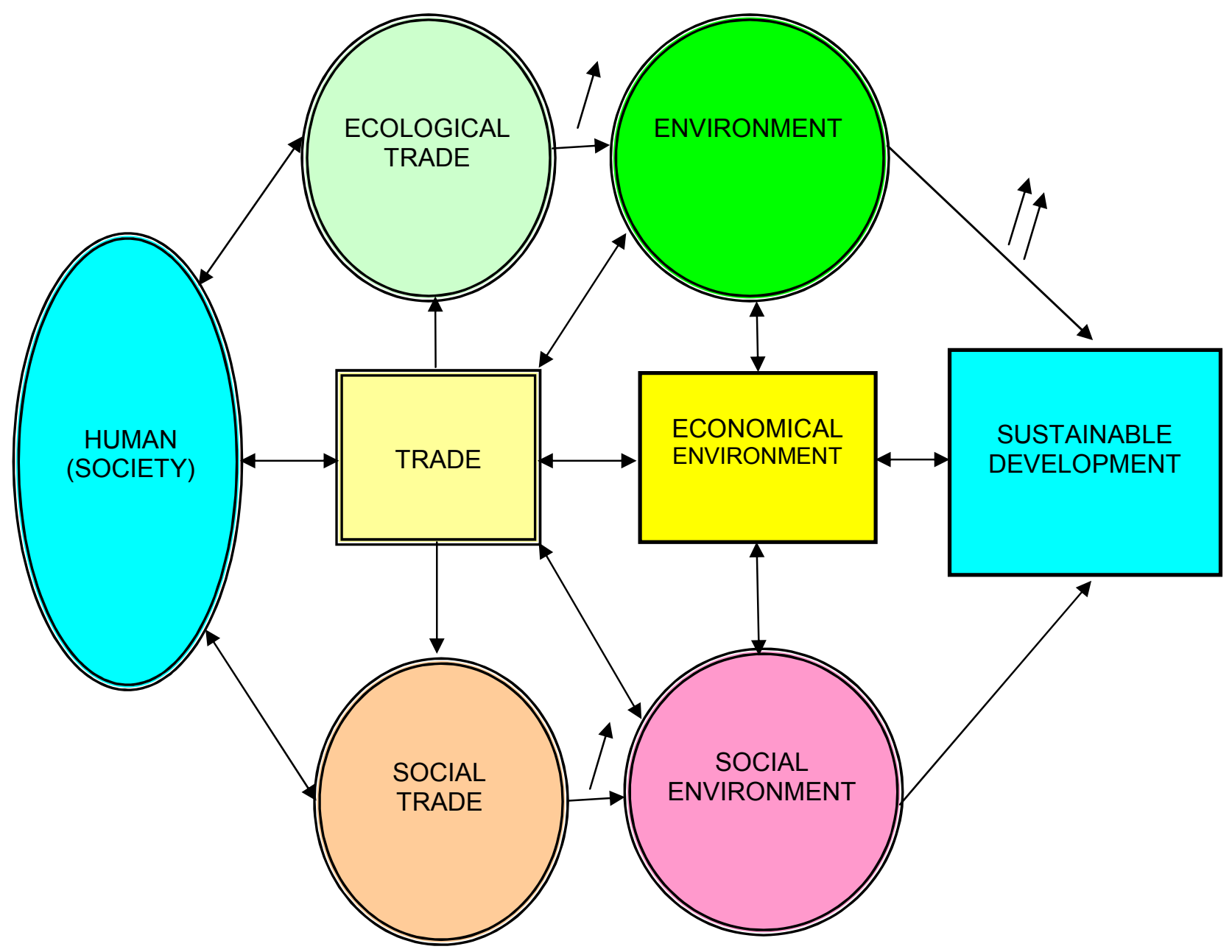

Fig. 3. The multiple correlation Human (Society) - Trade - Environment - Sustainable Development 
The following positive influences (favorable, $\boldsymbol{\lambda}, \boldsymbol{\Lambda}$ ) are identified:

$>$ Positive influence $(\boldsymbol{\nearrow})$ of the ecological trade on environment.

$>$ Positive influence $(\boldsymbol{\nearrow})$ of the social trade on social environment.

$>$ Clear positive influence ( $\nearrow$ ) of environment on sustainable development.

\section{ABOUt CORRELATION: TRADE - SUSTAINABLE DEVELOPMENT - ECONOMIC CRISIS}

The main types of the correlations Trade (C) - Sustainable Development (SD) - Economic Crisis (EC) are presented below (figure no. 4).

(III)

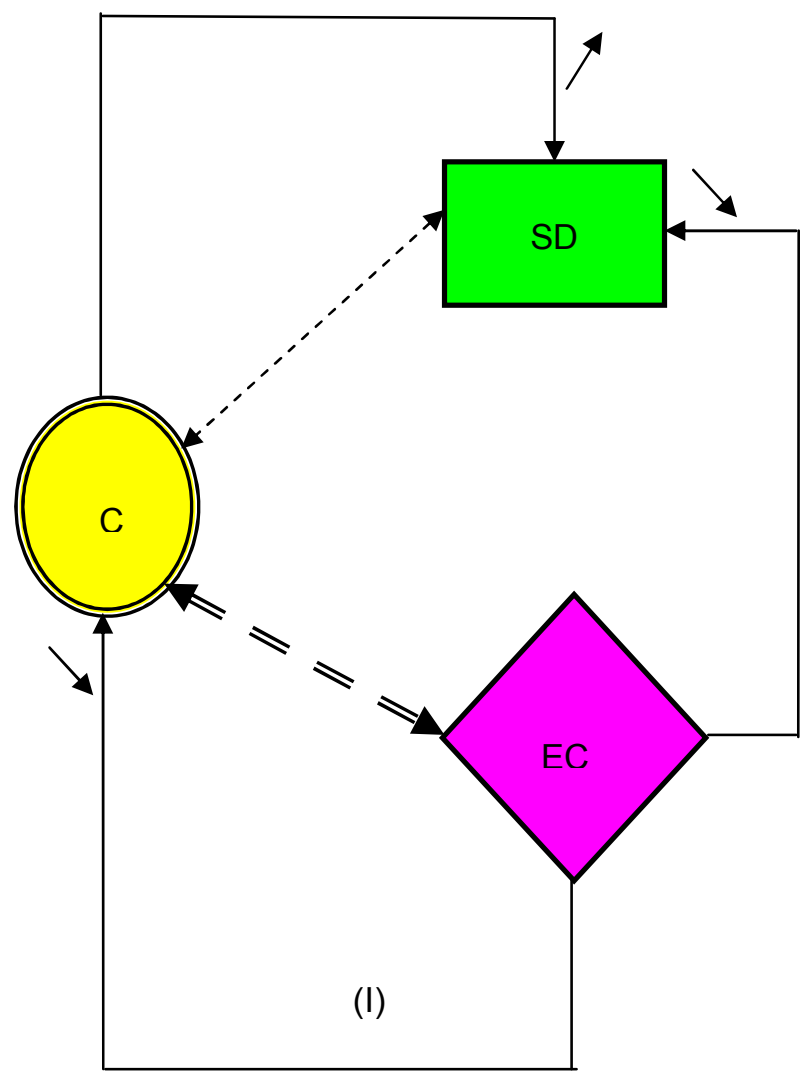

Fig. 4. The main types of the correlations Trade (C) Sustainable Development (SD) - Economic Crisis (EC)

There are three types of correlations:
I. The negative influence $(>$ ) of economic crisis on the trade (decrease of the sales volume).

II. The negative influence $(\searrow$ ) of economic crisis on sustainable development.

III. The positive influence $(\boldsymbol{\nearrow}$ ) of trade (ecological trade) on sustainable development

\section{THE COMMERCE, NONPERFORMING LOANS AND ELEMENTS OF RISK MANAGEMENT}

The nonperforming loans (NPL) are those loans for which principal or interest is due and left unpaid for 90 days or more (this period may vary by jurisdiction).

The NPL portfolio, along with the bank's collection ratio and the level of provisions recorded illustrate the quality of the entire portfolio and the overall credit policy of the bank $[4,8$, $10]$.

There are various reasons why the quality of bank loan portfolios deteriorate and research reveals that most reasons relate to the nature of the bank's credit culture. Below are listed the most usual drivers of loan portfolio deterioration:

$>$ Self - dealing refers to an overextension of credits to directors and large shareholders, while compromising sound credit principles under the pressure from related parties.

$>$ Compromise of credit principles refer to the granting with full knowledge of loans under unsatisfactory risk terms.

$>$ Anxiety over income outweighs the soundness of lending decisions, underscored by the hope that the risk will not materialize.

$>$ Incomplete credit information concerns loans granted without proper appraisal or borrower creditworthiness.

$>$ Complacency is typically manifested in a lack of adequate supervision of old, familiar borrowers, based on an optimistic interpretation of known credit weaknesses because of survival in distressed situations in the past.

$>$ Technical incompetence and poor selection of risks include a lack of ability among credit officers to analyze financial statements and obtain and evaluate pertinent credit information.

Measures to counteract credit risks normally comprise clearly defined policies that express the bank's credit risk management philosophy and the parameters within which credit risk is to be controlled.

Among the policies targeted at limiting the credit risk can be mentioned: policies on concentration and large exposures, adequate diversification, lending to connected parties or overexposures. 
Bank regulators have paid close attention to risk concentration by banks, the objective being to prevent banks from relying excessively on a large borrower or group of borrowers.

Modern prudential regulations usually stipulate that a bank should not make investments, grant large loans, or extend other credit facilities to any individual entity or related group of entities in excess of an amount that represents a prescribed percentage of the bank's capital and reserves.

According to international practice, a single client is an individual, a legal person or a connected group to which a bank is exposed.

Single clients are mutually associated or control (directly or indirectly) other clients, usually through a voting right of at least 15-20 percent, a dominant shareholding or the capacity to exercise a controlling influence on policy making and management. These clients' cumulative exposure may represent a singular risk to a bank if financial interdependence exists and their expected source of repayment is the same.

The second set of credit risk policies consist of the asset classification method, which employs a periodic evaluation of the collectability of the loan portfolio.

The general rule is that all assets for which a bank is taking a risk should be classified, including loans and advances, accounts receivable, investments, equity participations and contingent liabilities.

Asset classification, by means of which assets are classified at the time of origination and then reviewed and reclassified as necessary (according to the degree of credit risk) a few times per year, is a key risk management tool.

The periodical review considers loan service performance and the borrower's financial condition. Assets classified as "standard" or "specially mentioned" are typically reviewed twice per year, while critical assets are reviewed at least each quarter.

Banks determine classifications by themselves, but follow standards that are normally set by regulatory authorities. Standard rules for asset classification that are currently used are listed below:

$>$ Standard (pass) are loans for which the debt service capacity is considered to be beyond any doubt.

In general, fully secured loans by cash or cash substitutes (bank deposits, certificates, treasury bills etc) are usually classified in this category.

Specially mentioned (watch) are assets with potential weaknesses that may, if not checked or corrected, to weaken the asset as a whole or jeopardize the borrower's repayment capacity in the future.

In this category are included, for example, credits given through inadequate loan agreements, lack of control over the collateral, lack of proper documentation.
Loans to borrowers operating under economic or market conditions that may negatively affect the borrower in the future are also included in this category.

$>$ Substandard regard well defined credit weaknesses that jeopardize debt service capacity, in particular when the primary sources for repayment are insufficient and the bank must look to secondary sources for repayment, such as collateral, the sale of a fixed asset or refinancing. In this category can be included term credits to borrowers whose cash flow may not be enough to meet currently maturing debts, as well as short term loans and advances to borrowers for which the inventory-to-cash cycle is insufficient to repay the debt at maturity.

$>$ Doubtful are assets having the same weaknesses as substandard assets, but their collection in full is questionable on the basic of existing facts.

The possibility of loss is present, but certain factors that may strengthen the asset exist as well.

$>$ Loss regard assets that are considered uncollectible and of such little value that the continued definition as bankable assets is not warranted.

The inclusion in this category does not mean that the asset has absolutely no recovery or salvage value, but rather that it is neither practical nor desirable to defer the process of writing it off, even though partial recovery may be possible in the future.

The third set of credit risk management policies are policies regarding loss provisioning, by means of which allowances are set up at an adequate level as to absorb anticipated loss.

Asset classification is the one providing a basis for determining an adequate level of provisions for possible loan losses. The aggregate level of provisions, together with general loss reserves, indicates the capacity of a bank to effectively accommodate credit risk.

In determining an adequate reserve, all significant factors that affect the collectability of the loan portfolio should be considered.

These factors include the quality of credit policies and procedures, prior loss experiences loan growth, quality of management in the lending area, loan collection and recovery practices, changes in national and local economic and business conditions, and general economic trends.

Assessments of asset value should be performed systematically, consistently over time and in conformity with objective criteria.

Policies on loan-loss provisioning range from mandated to discretionary, depending on the banking system. In many countries, in particular those with fragile economies, regulators have established mandatory levels of provisions which are related to asset classification. 


\section{CONCLUSION}

The concept of sustainable development designates all forms and methods of socio-economic development, whose foundation is primarily to ensure a balance between these systems and socio-economic elements of natural capital.

Many correlations may be identified among trade, sustainable development and economic crisis. Of these correlations the following are most important:

$>$ Positive influence $(\boldsymbol{\nearrow})$ of the ecological trade on environment.

$>$ The negative influence $(\Delta)$ of the economic crisis on sustainable development.

$>$ Obvious positive influence $(\boldsymbol{\lambda})$ of environment on sustainable development.

The satisfaction of human needs and aspirations is the major objective of development.

The essential needs of a large number of people in developing countries (for food, clothing, shelter, jobs) are not being met yet, and beyond their basic needs these people have legitimate aspirations for an improved quality of life.

A world in which poverty and inequity are endemic will always be prone to ecological and other crises.

Sustainable development requires meeting the basic needs of all people and extending to everybody the opportunity to satisfy their aspirations for a better life.

The level of commerce depends on the specific credit resource. There are three sets of policies specific to credit risk management: policies aimed at limiting or reducing the credit risk, policies of asset classification and policies concerning loss provisioning.

In determining an adequate reserve, all significant factors that affect the collectability of the loan portfolio should be considered.

These factors include the quality of credit policies and procedures, prior loss experiences loan growth, quality of management in the lending area, loan collection and recovery practices, changes in national and local economic and business conditions, and general economic trends.
Assessments of asset value should be performed systematically, consistently over time and in conformity with objective criteria.

The main types of the triple correlation Commerce Sustainable Development - Risk Management reflect the leading position of Sustainable Development concept.

In this context, Commerce must realize the balance between the requirements of Sustainable Development and Risk Management.

\section{REFERENCES}

[1] Ammann, M., Credit Risk Valuation: methods, models and application, Springer Publishing House, Berlin, 2012, pp. 11-123.

[2] Cooper, G., The Origin of Financial Crises, Vintage Editure, USA, 2008 , pp. 25-73.

[3] Hodorogel, Roxana Gabriela, The Economic Crisis and its Effects on SMEs, Theoretical and Applied Economics Review, ISSN 1841-8678, No 5/2009 (534), Bucharest, 2009, pp. 31-38.

[4] Ioana, A., Managementul activită $\square$ ii financiar-contabile si analize economice. Teorie şi Aplica $\square$ ii., Ed. Politehnica Press, București, 2009, pp. 17-83.

[5] Ioana, A., Marketing Elements Mix in the Materials' Industry, Proceedings of the International Conference "European Integration New Challenges for the Romanian Economy", 4th Edition, May, 3031.2008, Oradea, 2008, pp. 51-54

[6] Ioana, A. (2007) Managementul producției în industria materialelor metalice. Teorie şi aplicații., Editura PRINTECH Bucureşti, ISBN 978-973-758-1232, 232 pg., Bucureşti.

[7] Ioana, A. (1998) The Electric Arc Furnaces (EAF) Functional and Technological Performances with the Preheating of the Load and Powder Blowing Optimization for the High Quality Steel Processing, PhD Thesis, University "Politehnica” of Bucharest, 1998, pp. .

[8] Ioana, A., Mirea, V., Bălescu, C. (2009) Analysis of Service Quality Management in the Materials Industry Using the BCG Matrix Method, Amphitheater Economic Review, Vol. XI, Nr. 26, June, Bucharest.

[9] Ioana, A., Nicolae, A., Bălescu, C. (2009) Elements of Metallurgical Marketing Mix (MMM), Metalurgia Review, ISSN 0461-9579, No 78/2009, Bucharest.

[10] Ioana, A., Semenescu, A., Preda, C.F. (2012) Management Strategic. Teorie şi Aplicații. Editura Matrix Rom, București, ISBN 978-973755-8268, 204 pg, Bucureşti.

$[11] * * *$, http://www.earthpolicy.com

$[12] * * *$, http://evado.ro

\section{Creative Commons Attribution License 4.0} (Attribution 4.0 International, CC BY 4.0)

This article is published under the terms of the Creative Commons Attribution License 4.0

https://creativecommons.org/licenses/by/4.0/deed.en_US 